Çukurova Üniversitesi Mühendislik Mimarlık Fakültesi Dergisi, 33(4), ss. 45-56, Aralık 2018

Çukurova University Journal of the Faculty of Engineering and Architecture, 33(4), pp. 45-56, December 2018

\title{
Yedioluk-Kozan (Adıyaman) Bölgesi İçme Sularının Karakteristiklerinin Hidrojeolojik Açıdan İncelenmesi
}

\author{
Yusuf URAS ${ }^{* 1}$, Yağmur UYSAL ${ }^{2}$, Mehmet Nihat YILMAZ ${ }^{1}$, Merve PAKSOY ${ }^{1}$ \\ ${ }^{1}$ Kahramanmaraş Sütçü Imam Üniversitesi, Mühendislik Mimarlık Fakültesi, \\ Jeoloji Mühendisliği Bölümü, Kahramanmaraş \\ ${ }^{2}$ Kahramanmaraş Sütçü İmam Üniversitesi, Mühendislik Mimarlık Fakültesi, \\ Çevre Mühendisliği Bölümü, Kahramanmaraş
}

Öz

Geliş tarihi: 15.01.2018 Kabul tarihi: 25.12.2018

Bu çalışmanın amacı, Adıyaman ili sınırları içerisinde yer alan Yedioluk ve Kozan bölgesindeki içme suyu kaynaklarının hidrojeokimya, izotop jeokimyası ve tıbbi jeoloji yönünden araştırılmasıdır. Adıyaman merkezinin kuzeydoğusunda önemli bir su potansiyeline sahip olan bölgede 8 adet içme suyu kaynağı yer alır. Üst Jura-Alt Kretase yaşlı Koçali Kompleksi ana akifer niteliğinde olup Yedioluk ve Kozan bölgelerinde içme suyu kaynaklarının önemli bir bölümü bu akiferden boşalır. Bölgeden bir yıl boyunca farklı mevsimlerde (yağışlı/kurak dönemlerde) alınan su örneklerinde $\delta^{18} \mathrm{O}(\mathrm{Oksijen})$ $\delta^{2} \mathrm{H}($ Döteryum) ve (Trityum) analizleri yapılmıştır. Kaynakların su kalitesini belirlemek amacıyla, sıcaklık, pH, iletkenlik, alkalinite, iz element derişimleri, anyon-katyon ölçümleri ve metal derişimleri, iyon kromatografisi (IC) ve ICP-OES kullanılarak gerçekleştirilmiştir. İzotop analizlerinden faydalanılarak suların kökenine ait bilgilere ulaşılmış, elde edilen sonuçlar, incelenen su kaynaklarının soğuk sular sınıfında olduğunu göstermiştir. Ayrıca, bölgedeki su kaynaklarının çoğunda yüksek miktarda nitrat iyonu derişimine rastlandığı, bu su kaynaklarının içme suyu kaynağı olarak kullanılmadan önce arıtımdan geçirilmesi sonucuna ulaşılmıştır.

Anahtar Kelimeler: Hidrojeokimya, İ̧̧me suyu, İzotop jeokimyası, Tıbbi jeoloji

\section{Hydrogeological Investigation of the Characteristics of the Drinking Water Sources of the Yedioluk-Kozan (Adiyaman) Region}

\begin{abstract}
The aim of this study is to investigate drinking water sources in the Yedioluk and Kozan regions within the boundaries of Adiyaman province in terms of hydrogeochemistry, isotope geochemistry and medical geology. There are 8 drinking water sources which have important water potentials in the northeast of the Adıyaman center. The Upper Jurassic-Lower Cretaceous Koçali Complex is the main aquifer and a significant part of the drinking water resources are discharged from this aquifer. Yedioluk and a significant portion of the drinking water resources of the Kozan region are supplied from this aquifer. Water quality parameters were investigated in the water samples obtained from 8 different springs, and isotope analyzes were also performed by IRMS method for $\delta^{18} \mathrm{O}$ (Oxygen)- $\delta^{2} \mathrm{H}$ (Deuterium), and IAEA method for TU (Tritium). Samples were taken for the analyses at wet/dry seasons for one year. Ionchromatography (IC) and ICP-OES were used to determine several parameters such as trace elements,
\end{abstract}

*Sorumlu yazar (Corresponding author): Yusuf URAS, uras74@gmail.com 
metal sandanion-cationconcentrations. Information abouttheorigin of the waters was obtained by using the isotope analysis, and there sults showed that the studied water resources are in the cold water class. In addition, it was found that the majority of the water resources in there gion have high concentrations of nitrateions. Thus, it is proposed that, waters should be treated by using water treatmentmet hods for there moval of nitrateions before bein gused as a source of drinking water.

Keywords: Drinking water, Hydrogeochemistry, Isotope geochemistry, Medical geology

\section{GíRiș}

Hidrojeoloji, yeraltı jeolojik ortamı boyunca su hareketinin incelendiği bir bilim dalıdır ve jeolojik yap1 içindeki gözeneklerde suyun bulunuşu ile ilgili özellikleri inceler. Su, canlının ve canlılığın her şeyidir. Yeryüzünün $3 / 4$ 'ünün su ile kaplı olması, dünyada su bolluğu olduğu görünümü veriyorsa da içilebilir nitelikteki su oranı ancak $\% 0,74$ civarındadır [1].

Yeraltı suları, hidrolojik çevrim esnasında yeraltı katmanlarından geçerken bünyelerine bu tabakalardaki maddeleri de çözerek alırlar. Suyun geçtiği ortam karakteristiklerine bağlı olarak kimyasal yapısı da değişim gösterir ve böylelikle su saf $\mathrm{H}_{2} \mathrm{O}$ olmaktan çıkar. Suya katılan organik veya inorganik kökenli materyallerin cinsi ve miktarları ortam yapısı ile değişmekle beraber suyun potansiyeline ve hidrolik koşullara bağlı olarak da değişim gösterir. Hidrolik koşullar suyun miktarı, akım karakteristikleri ve yeraltının jeolojik yapısına bağlıdır. Bunun yanı sıra suyun kimyasal yapısını etkileyen diğer bir faktör de iklimdir. $\mathrm{Bu}$ sebeple, yapılan analizler ile yeraltı sularının çevresel izotop içeriklerinin belirlenmesi, bu suyun köken ve yaşını, kayaç-yeraltı suyu arasındaki ilişkileri ve beslenme alanının özelliklerini de ortaya koyar.

Yeraltı sularının hidrojeolojik özelliklerine dayanarak bu suların jeokimyası, hidrolojisi, fiziksel-kimyasal özellikleri ve tıbbi jeoloji açısından kullanılabilirliği gibi özellikler değerlendirilebilmektedir. Su kalitesini belirlemek ve içme/kullanma suyu amaçlı değerlendirmek için sularda çeşitli fiziksel ve kimyasal parametreler incelenir. $\mathrm{Bu}$ parametreler fiziksel (sicaklık, $\mathrm{pH}$, bulanıklık, renk, askıda katı maddeler), kimyasal (çözünmüş formdaki organik maddeler, inorganik anyon ve katyonlar) ve biyolojik olmak üzere genel olarak 3 kategoride toplanır. Örneğin Biyolojik Oksijen İhtiyacı (BOİ), Kimyasal oksijen ihtiyacı (KOI), Toplam organik karbon (TOK), Çözünmüş oksijen (ÇO), Azot (organik azot $(\mathrm{TN})$, amonyum $\left(\mathrm{NH}_{4}{ }^{+}\right)$, nitrat $\left(\mathrm{NO}_{3}{ }^{-}\right)$ve nitrit $\left(\mathrm{NO}_{2}^{-}\right)$) ve fosfor (TP) ve ağır metal iyonları bu kategoriye girmektedir.

$\mathrm{Bu}$ çalışmada, Adıyaman kent merkezinin yaklaşık $20 \mathrm{~km}$ kuzeydoğusunda yer alan Yedioluk-Kozan bölgesindeki su kaynaklarının su kalitesi ve hidrojeokimya açısından değerlendirilmesi amaciyla 8 faklı kaynaktan alınan su numunelerinde çözünmüş inorganik parametreleri belirlemek amaciyla anyon, katyon analizleri, ana ve iz elementler ve izotop analizleri yapılmıştır. Farklı kaynak noktaları olarak, Hamam Çeşmesi (HC-1), Ziyaret tepe (ZT-2), Köy Çeşmesi (YO-3), Yatır Pınarı (YP-4), Aşağı Köy Çeşmesi (AC-5), Kozan Köy Çeşmesi (KC-6), Sondaj Yeri (KS-7) ve Kozan Köyü Pınarı (KP-8) seçilmiştir (Şekil 1). $\mathrm{Bu}$ kapsamda, içme suyu kaynaklarının bulunduğu bölgenin genel jeolojisi, hidrojeolojisi, izotop jeolojisi, su kimyası ve tıbbi jeolojisi ile ilgili incelemeler yapılmıştır.

\section{MATERYAL VE METOT}

\subsection{Materyal}

Çalışma alanı olarak seçilen Yedioluk-Kozan (Adryaman) mevkiinde bulunan 8 farklı kaynak suyundan bir y1l boyunca 96 adet su numunesi alınarak yerinde ve laboratuarda çeşitli analizler gerçekleştirilmiştir. İnceleme alanından alınan su kaynaklarının jeokimyasal, izotop jeokimyası ve hidrokimyasal incelemeleri yapılarak suların kökeniyle ilgili tüm özelliklerin ortaya konulması hedeflenmiştir. Ayrıca su kaynağının tıbbi jeoloji açısından değerlendirilmesi yapılmıştır. 


\subsection{Metot}

Arazi çalışmaları kapsamında örnekler analiz edilmek üzere laboratuvara gönderilmiştir. Laboratuvarda saf su ile yıkanan 1 L'lik numune kapları sahada örneklenecek su ile tekrar çalkalanmış ve böylece olası kirlenme engellenmiştir. pH, çözünmüş oksijen (ÇO), iletkenlik (EC), sicaklık gibi parametreler örnekleme yerinde anlık olarak ölçülmüştür. Analiz amaciyla laboratuvara getirilen örnekler buzdolabında $\left(+4 \quad{ }^{\circ} \mathrm{C}\right)$ muhafaza edilmiştir. Örneklerde ağır metal ve anyon-katyon analizleri, ICP-OES (İndüktif Olarak Eşleşmiş Plazma Optik Emisyon Spektrometresi) ve IC (İyon Kromatografisi) cihazları kullanılarak KanadaACME (Analytical Laboratories) laboratuarlarında gerçekleştirilmiştir. Suların izotop analizleri ise (TU (trityum), $\delta^{18} \mathrm{O}$ (oksijen) ve $\delta^{2} \mathrm{H}$ (döteryum)) DSİ TAKK Dairesi İzotop Laboratuvarlarında IRMS metodu ve IAEA deney standartları kullanılarak gerçekleştirilmiştir.
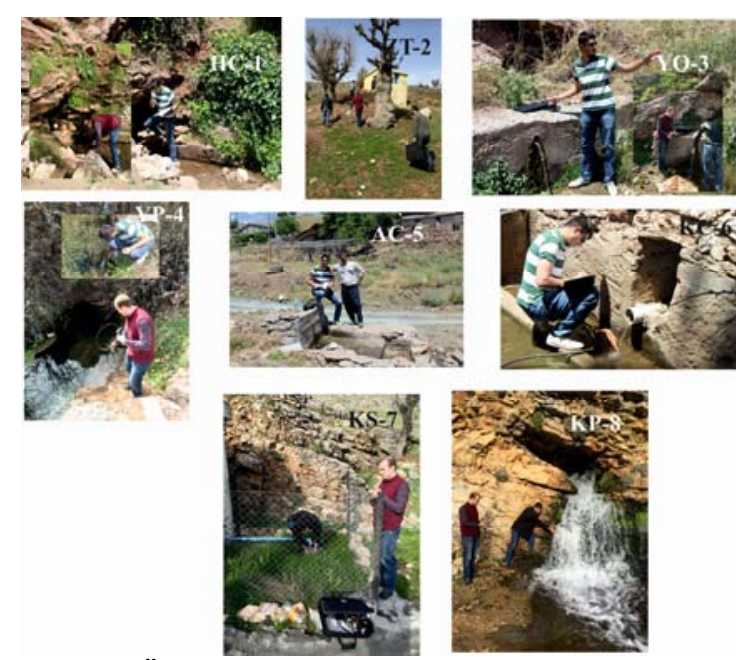

Şekil 1. Örnekleme noktalarından fotoğraflar

\section{BULGULAR}

\subsection{Bölge Jeolojisi}

Çalışma alanındaki litolojik birimler Adıyaman İli kuzeyinde, Gölbaşı-Gerger ilçeleri arasında kalan alan ile Diyarbakır İli Korudağ-Çermik-Çüngüş dolaylarında yüzeyleyen Koçali Karmaşı̆̆ı, serpantinitler, sedimanter kayalar ve volkanitlerden oluşmaktadır [2-3-4]. İçme suyu kaynaklarının bulunduğu çalışmalarının jeoloji haritası revize edilmiştir (Şekil 2).

Bölgede yüzeyleyen birimler yaşlıdan gence doğru şu şekildedir: Soğuk suları depolayan Jura-Alt Kratese yaşlı volkano-sedimanter ve ofiyolitik kayaç topluluğundan oluşan Koçali kompleksi, Üst Kampaniyen-Paleosen yaşlı karasal-geçişsığ/deniz-havza ortamı kayaçlarından yapılı Şırnak Grubu ve tebeşirli kireçtaşı, tebeşirli marn, mercek ve kanal görünümlü kireçtaşı, çört-silisifiye kireçtaşlarından oluşan Midyat grubu (Gaziantep formasyonu). Bunların üzerine Alt Eosen-Alt Oligosen yaşlı kireçtaşı ve dolomitlerden oluşan Hoya Formasyonu gelmektedir [5]. Midyat grubu üzerinde açılı uyumsuzlukla kumtaşı-silttaş1-şeylmarn ardalanmalı Üst Miyosen yaşlı Şeymo formasyonu yer alır. Alttaki tüm birimlerin üzerine kırmızımsı kahve-gri renkli, farklı boyutlu çakıl ve kumdan oluşan, silt ve kil türü malzemenin ilave olduğu Kuvaterner yaşlı alüvyon gelmektedir.

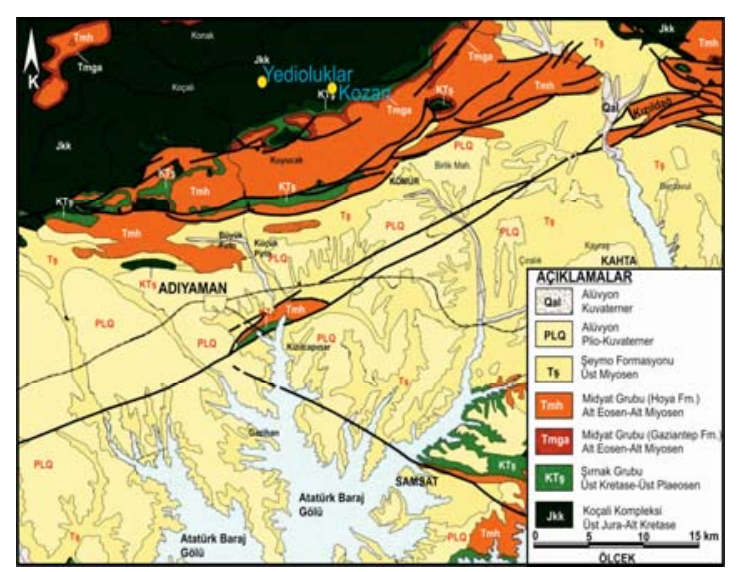

Şekil 2. Çalışma alanının jeoloji haritası [2]

\subsection{Bölgenin Hidrojeolojisi}

Adıyaman karasal bir iklime sahip olduğundan; yazları sıcak ve kurak, kışları ise soğuk ve yağışlı geçmektedir. Doğu Anadolu ile Akdeniz Bölgeleri arasında geçit konumunda olan ilin iklimi zaman zaman değişiklik göstermektedir. T.C. Meteoroloji Genel Müdürlüğü'nden alınan verilere göre, ilin en 
sıcak ayları Haziran, Temmuz ve Ağustos aylarıdır ve genellikle sonbaharın ortalarından ilkbaharın sonuna kadar yağış alan ilin yıllık yağış ortalaması $52,6 \mathrm{~kg} / \mathrm{m}^{2}$ 'dir. Yağmur, genellikle sonbaharın ortalarından ilkbahar sonuna kadar yağmakta ve uzun yıllar yağış ortalaması $700 \mathrm{~kg} / \mathrm{m}^{2}$ dir. Yukarıda anlatılan iklim özellikleri nedeniyle Yedi Oluklar-Kozan sahası yüzey suları bakımından oldukça zengin bir potansiyele sahiptir. Bu sahada geniş bir alanda yüzeyleyen Koçali Formasyonu litolojik yapısı nedeniyle oldukça eklemli ve kırıklı bir yapı sunmaktadır. $\mathrm{Bu}$ çalışmanın gerçekleştirildiği Yedioluk-Kozan çalışma alanı ve çevresinin kireçtaşları ile çevrili ve çatlaklı/kırıklı yapılı olması nedeniyle yüksek geçirgenlik özelliğine sahip olduğu için akifer kalitesi üzerinde etkisinin olduğu düşünülmektedir.

\subsection{Bölgenin Hidrojeokimyasal Karakteristikleri}

Yedi Oluk-Kozan sahasındaki su kaynaklarının kalitesinin belirlenmesi amaciyla, 1 y1l boyunca sicaklık, pH, iletkenlik, alkalinite, iz element, anyon-katyon ve metal derişimi ölçümleri yapılmıştır. Yıl boyunca $10{ }^{\circ} \mathrm{C}-14{ }^{\circ} \mathrm{C}$ arasında değişen su sıcaklık değerleri, su kaynaklarının genel olarak soğuk su sınıfinda yer aldığını göstermektedir. Yerinde yapılan Çözünmüş Oksijen ölçümlerinde tüm su kaynaklarının ÇO değerlerinin birbirine yakın olduğu (\%2-5) belirlenmiştir. Sularda tuzluluk miktarını belirlemek için yapılan $\mathrm{Na}^{+}$iyonu konsantrasyonu ölçümleri derişimin 0,21-14,03 ppm aralığında ve bu değerlerin WHO (1998)'e [6] göre içme suları için izin verilen sınır değerin (200 ppm) çok altında olduğunu göstermektedir. $\mathrm{Bu}$ durum, bölgenin içme suyu kaynaklarındaki tuzluluğun çok düşük olduğunu gösteren bir veri olarak değerlendirilmiştir. İnceleme alanındaki su örneklerine ait ABD tuzluluk diyagramları verilmiştir. Wilcox diyagramına göre çok iyi-iyi (Şekil 4), ABD Tuzluluk diyagramına göre HC-1, ZT-2, YO-3, YO-4, AC-5, KC-6, KS-7, KP-8 kaynağından alınan sular "C2-S1" sular sinıfına düşmektedir.

Tuzluluk ölçüm sonuçlarını destekleyen diğer bir veri de Elektriksel İletkenlik (EC) sonuçlarıdır. Numune alımı sirasında yapılan yerinde ölçümlerde sularıniletkenlik değerlerinin çok düşük olması $(270-572 \mu \mathrm{s} / \mathrm{cm})$, su kaynaklarında çözünmüş anyon-katyon içeriklerinin ve tuzluluk değerlerinin çok düşük olduğunu gösteren diğer bir veridir.

Kimyasal analiz sonuçlarından inceleme alanındaki suların hidrokimyasal fasiyesleri belirlenmiştir. HC-1, ZT-2, YO-3, YP-4, AC-5, $\mathrm{KC}-6, \mathrm{KS}-7, \mathrm{KP}-8$ Piper [7] diyagramına göre, litrede eşdeğer gram cinsinden toplam çözünmüş iyon derişimleri \%50'yi geçmeyen, sular karış1k sular sınıfına girmektedir (Şekil 5). Piper diyagramına göre numuneler 6 . Bölgeye düşmektedir. Karbonat olmayan sertliği \%50'den fazla sulara aittir ve karbonat olmayan sertliği yani kalıcı sertliği geçici sertliğine göre daha yüksek olan sulardır. $\mathrm{Bu}$ sular yüksek miktarda $\mathrm{CaSO}_{4}$, $\mathrm{MgSO}_{4}, \mathrm{CaCl}_{2}, \mathrm{MgCl}_{2}{ }^{\prime} \mathrm{l}_{1}$ sulardır ve sertlikleri kaynatma yolu ile giderilemez. Sadece iyon değiştirme, kireçle muamele gibi kimyasal setlik giderme işlemleri gerektirirler.

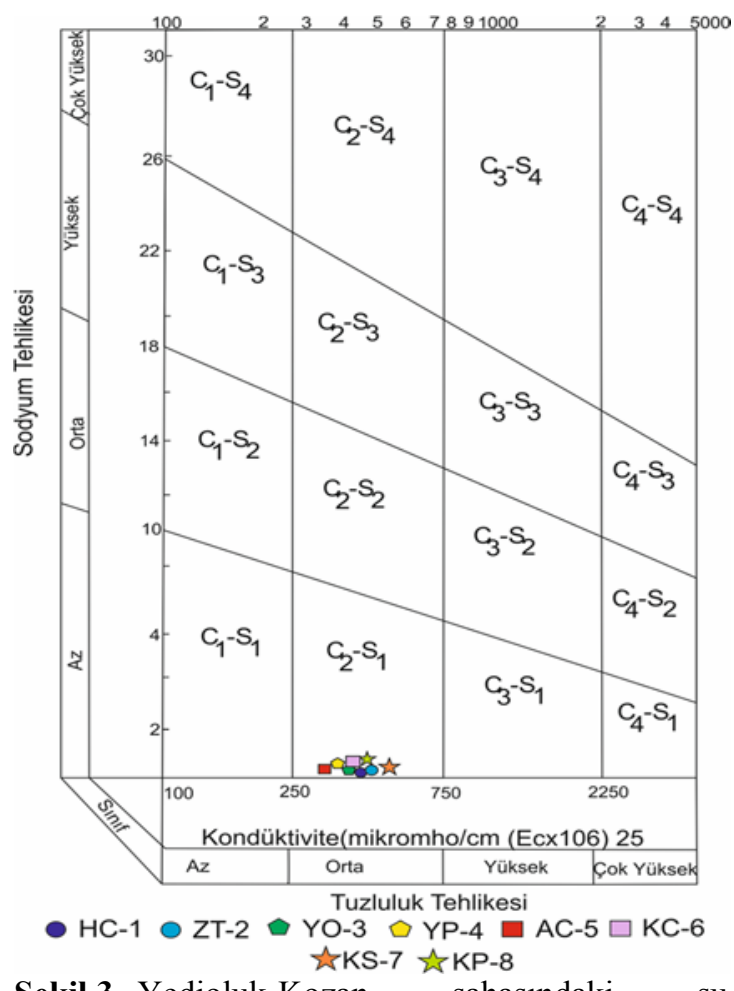

Şekil 3. Yedioluk-Kozan sahasındaki su kaynaklarının ABD Tuzluluk diyagramı 
Yedioluk-Kozan sahasındaki içme suyu kaynaklarından alınan su örneklerinin anyon-katyon derişim sonuçları (Çizelge 2) Scholler grafiği kullanılarak yorumlanmıştır (Şekil 6). Buna göre iyon bollukları katyonlarda $\mathrm{Mg}^{+2}>\mathrm{Ca}^{+2}>\mathrm{Na}^{+}+\mathrm{K}^{+}$, anyonlarda ise $\mathrm{HCO}_{3}>\mathrm{SO}_{4}^{-2}>\mathrm{Cl}^{-}$olarak belirlenmiştir. Yedioluk-Kozan sahasındaki içme suyu kaynakları, Schoeller diyagramında klorür derişimine göre "olağan klorürlü sular" sınıfina, sülfat derişimine göre "olağan sülfatlı sular" sınıfına ve Karbonat+Bikarbonat derişimine göre "Hipokarbonatlı sular" sinıfina girmektedir (Şekil 5).

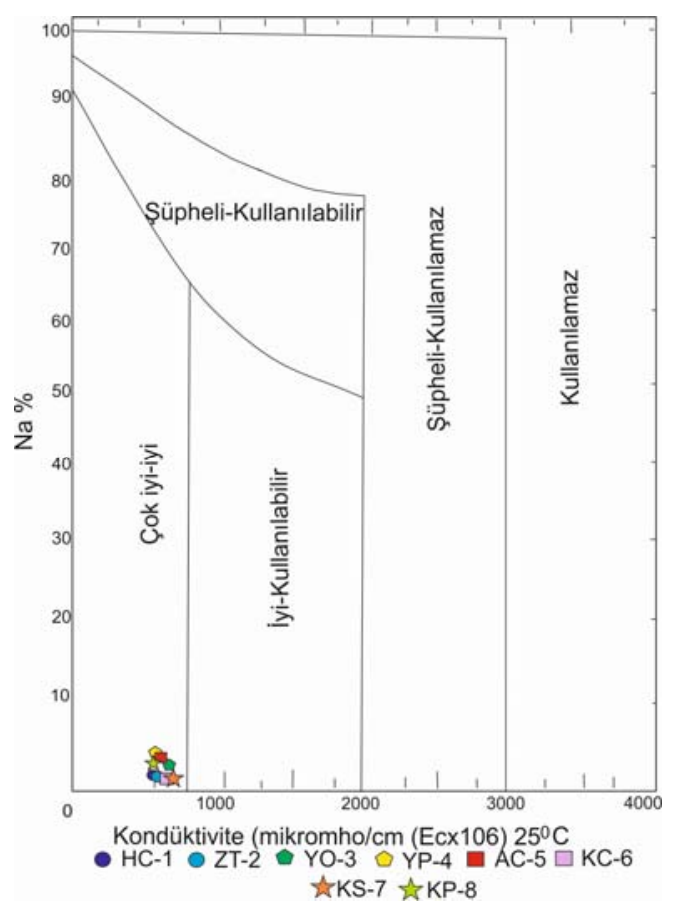

Şekil 4. Yedioluk-Kozan sahasındaki su kaynaklarının Wilcox diyagramı

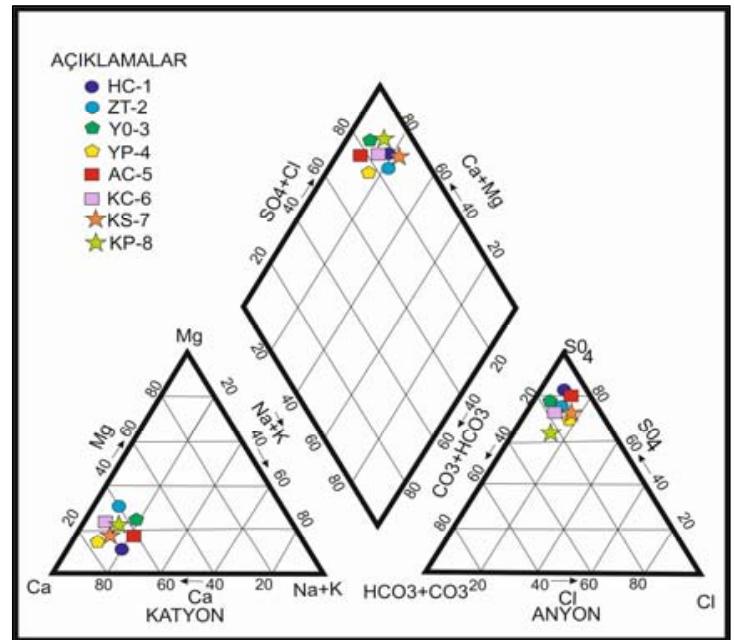

Şekil 5. Yedioluk-Kozan sahasındaki su kaynaklarının Piper diyagramı 
Çizelge 1. Yedioluk-Kozan sahasındaki su kaynaklarının anyon katyon değerleri

\begin{tabular}{|c|l|l|}
\hline Örnek No & Katyon Suralamasi & Anyon Siralaması \\
\hline $\mathrm{HC}-1$ & $\mathrm{Mg}^{+2}>\mathrm{Ca}^{+2}>\mathrm{Na}^{+}+\mathrm{K}^{+}$ & $\mathrm{HCO}_{3}>\mathrm{SO}_{4}{ }^{-2}>\mathrm{CI}^{-}$ \\
\hline ZT-2 & $\mathrm{Mg}^{+2}>\mathrm{Ca}^{+2}>\mathrm{Na}^{+}+\mathrm{K}^{+}$ & $\mathrm{HCO}_{3}>\mathrm{SO}_{4}{ }^{-2}>\mathrm{CI}^{-}$ \\
\hline YO-3 & $\mathrm{Mg}^{+2}>\mathrm{Ca}^{+2}>\mathrm{Na}^{+}+\mathrm{K}^{+}$ & $\mathrm{HCO}_{3}>\mathrm{SO}_{4}{ }^{-2}>\mathrm{CI}^{-}$ \\
\hline YP-4 & $\mathrm{Mg}^{+2}>\mathrm{Ca}^{+2}>\mathrm{Na}^{+}+\mathrm{K}^{+}$ & $\mathrm{HCO}_{3}>\mathrm{SO}_{4}^{-2}>\mathrm{CI}^{-}$ \\
\hline AC-5 & $\mathrm{Mg}^{+2}>\mathrm{Ca}^{+2}>\mathrm{Na}^{+}+\mathrm{K}^{+}$ & $\mathrm{HCO}_{3}>\mathrm{SO}_{4}^{-2}>\mathrm{CI}^{-}$ \\
\hline KC-6 & $\mathrm{Mg}^{+2}>\mathrm{Ca}^{+2}>\mathrm{Na}^{+}+\mathrm{K}^{+}$ & $\mathrm{HCO}_{3}>\mathrm{SO}_{4}^{-2}>\mathrm{CI}^{-}$ \\
\hline KS-7 & $\mathrm{Mg}^{+2}>\mathrm{Ca}^{+2}>\mathrm{Na}^{+}+\mathrm{K}^{+}$ & $\mathrm{HCO}_{3}>\mathrm{SO}_{4}^{-2}>\mathrm{CI}^{-}$ \\
\hline KP-8 & $\mathrm{Mg}^{+2}>\mathrm{Ca}^{+2}>\mathrm{Na}^{+}+\mathrm{K}^{+}$ & $\mathrm{HCO}_{3}>\mathrm{SO}_{4}^{-2}>\mathrm{CI}^{-}$ \\
\hline
\end{tabular}

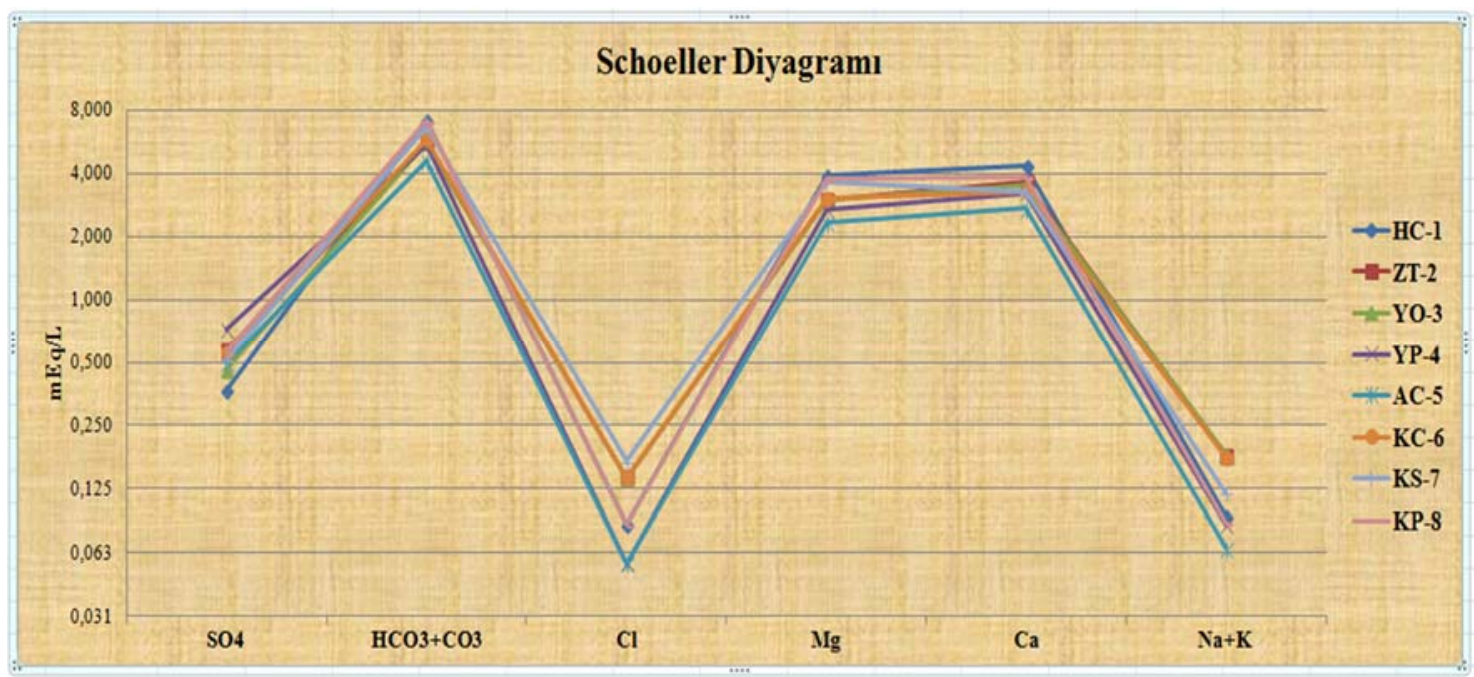

Şekil 6. Yedioluk -Kozan sahası su kaynaklarının Schoeller diyagramı

\section{3. İzotop Hidrojeolojisi}

Yedioluk-Kozan sahasında bulunan su kaynaklarında akiferlerin kökeni, beslenme alanı ve su-kayaç etkileşim sürecinin belirlenebilmesi amacıyla çevresel izotop içerikli çalışmalar yapılmıştır. $\mathrm{Bu}$ çalışmalarda radyoizotop olarak trityum $\left({ }^{3} \mathrm{H}\right)$, kararlı (duraylı) izotop olarak da oksijen-18( $\left({ }^{18} \mathrm{O}\right)$ ve döteryum $\left({ }^{2} \mathrm{H}\right)$ izotoplarından yararlanılmıştır. İnceleme alanındaki su kaynaklarının olası beslenme yükseltilerinin hesaplanmasında $\delta^{18} \mathrm{O}$ ve $\delta^{2} \mathrm{H}$ değerleri kullanılmıştır. $\delta^{18} \mathrm{O}$ ve $\delta^{2} \mathrm{H}$ arasındaki değişim oranı ilişkisi global meteorik su doğrusu Craig [8] ve Akdeniz su doğrusu baz alınarak incelenmiştir.

Çalışma sahasından bir yıl içerisinde farklı aylardan (kurak-yağışlı) alınan su örneklerinden HC-1 için kurak/yağışlı dönemde sırası ile $\delta^{18} \mathrm{O}:-8.21 /-8,01 ; \delta^{2} \mathrm{H}:-44,68 /-44,30,{ }^{3} \mathrm{H}: 4,42 / 4,30$; ZT-2 için kurak/yağ 1 şlı dönemde $\delta^{18} \mathrm{O}:-8,74 /-8,55$, $\delta^{2} \mathrm{H}:-46,15 /-47,10, \quad{ }^{3} \mathrm{H}: \quad 3,84 / 3,55$; YO-3 için $\delta^{18} \mathrm{O}:-8,59 /-8,47 ; \delta^{2} \mathrm{H}:-47,70 /-47,30,{ }^{3} \mathrm{H}: 3,64 / 3,60$; ve YP-4 için $\delta^{18} \mathrm{O}:-8,85 /-8,68 ; \delta^{2} \mathrm{H}:-48,02 /-47,79$, ${ }^{3} \mathrm{H}: 3,04 / 4,35$ arasında değiştiği saptanmıştır. 
Çizelge 2. Su örneklerinin sıcaklık, pH ve iletkenlik değerleri ile jeokimyasal analiz sonuçları

\begin{tabular}{|c|c|c|c|c|c|c|c|c|}
\hline NUMUNE & HC-1 & ZT-2 & YO-3 & YP-4 & AC-5 & KC-6 & KS-7 & KP-8 \\
\hline Sicaklık ( $\left({ }^{\circ} \mathrm{C}\right)$ & $10-14$ & $10-14$ & $9-14$ & $10-14$ & $9-14$ & $10-14$ & $10-14$ & $10-14$ \\
\hline pH & $7,6-9,2$ & $7,4-9,2$ & $7,5-9,2$ & $7,6-9,2$ & $7,5-9,2$ & $7,6-9,2$ & $7,4-9,2$ & $7,4-9,2$ \\
\hline $\mathrm{EC}(\boldsymbol{\mu S} / \mathrm{cm})$ & $270-492$ & $271-502$ & $285-505$ & $282-572$ & $285-505$ & $282-572$ & $271-504$ & $282-482$ \\
\hline DO (\%) & $2-5$ & $2-4$ & $2-4$ & $2-4$ & $2-4$ & $2-4$ & $2-4$ & $2-4$ \\
\hline $\mathrm{Na}^{+}(\mathbf{p p m})$ & $3,09-5,09$ & $1,75-3,09$ & $10,02-13,94$ & $3,52-5,83$ & $0,21-1,56$ & $2,30-8,60$ & $5,03-11,50$ & $2,21-3,63$ \\
\hline $\mathbf{K}^{+}(\mathbf{p p m})$ & $2,08-4,75$ & $0,53-1,80$ & $0,65-1,32$ & $0,21-0,42$ & $0,28-1,35$ & $0,25-0,45$ & $0,35-0,95$ & $0,21-0,43$ \\
\hline $\mathrm{Ca}^{+2}(\mathrm{ppm})$ & $40,00-48,79$ & $11,29-15,54$ & $65,96-87,63$ & $55,40-71,45$ & $4,21-6,74$ & $33,10-57,05$ & $45,25-65,64$ & $12,49-25,65$ \\
\hline $\mathbf{M g}^{+2}(\mathbf{p p m})$ & $111,05-130,09$ & $120,39-132,57$ & $101,2-119,39$ & $100,02-117,90$ & $103,21-127,05$ & $104,54-117,64$ & $103,55-112,82$ & $120,04-156,04$ \\
\hline $\mathrm{Cl}^{-}(\mathbf{p p m})$ & $3,65-7,23$ & $2,34-6,52$ & $12,32-21,22$ & $2,14-4,75$ & $2,56-2,79$ & $1,53-2,81$ & $1,14-2,67$ & $1,22-3,02$ \\
\hline $\mathrm{HCO}_{3}{ }^{-}(\mathrm{ppm})$ & $256-283$ & $148,3-201,15$ & $224-320$ & $212-245$ & $110-141$ & $153-200$ & $220-271$ & $252-294$ \\
\hline $\mathrm{CO}_{3}^{-2}(\mathrm{ppm})$ & 0,00 & 0,00 & 0,00 & 0,00 & 0,00 & 0,00 & 0,00 & 0,00 \\
\hline $\mathrm{SO}_{4}^{-2}(\mathrm{ppm})$ & $8,05-9,36$ & $5,92-6,35$ & $17,70-21,92$ & $8,23-10,88$ & $4,25-4,54$ & $6,75-18,21$ & $8,40-12,43$ & $6,58-9,05$ \\
\hline $\mathrm{Fe}^{+2}(\mathrm{ppb})$ & 10 & 10 & 10 & 10 & 10 & 10 & 10 & 10 \\
\hline $\mathrm{NO}_{3}{ }^{-}(\mathrm{ppm})$ & $13,28-35,92$ & $10,03-25,02$ & $85,01-92,35$ & $45,52-65,33$ & $56,45-86,75$ & $60,32-75,87$ & $2,79-5,65$ & $0,65-0,93$ \\
\hline $\mathrm{NH}_{4}{ }^{+}(\mathrm{ppm})$ & $0,02-0,07$ & $0,02-0,07$ & $0,02-0,07$ & $0,03-0,08$ & $0,03-0,08$ & $0,07-0,07$ & $0,07-0,08$ & $0,07-0,08$ \\
\hline $\mathrm{NO}_{2}^{-}(\mathrm{ppm})$ & 0,1 & 0,1 & 0,1 & 0,1 & 0,1 & 0,1 & 0,1 & 0,1 \\
\hline $\mathrm{PO}_{4}^{-3}(\mathrm{ppm})$ & 0,1 & 0,1 & 0,1 & 0,1 & 0,1 & 0,1 & 0,1 & 0,1 \\
\hline $\mathrm{F}^{-1}(\mathrm{ppm})$ & $0,03-0,13$ & $0,04-0,11$ & $0,02-0,07$ & $0,04-0,08$ & $0,04-0,08$ & $0,04-0,08$ & $0,03-0,08$ & $0,04-0,09$ \\
\hline
\end{tabular}

Benzer şekilde, AC-5 için kurak ve yağışı dönemlerde siras1 ile $\delta^{18} \mathrm{O}:-8,88 /-8,37$, $\delta^{2} \mathrm{H}:-47,89 /-44,49, \quad{ }^{3} \mathrm{H}: 4,55 / 2,48 ; \quad \mathrm{KC}-6 \quad$ için $\delta^{18} \mathrm{O}:-8,44 /-8,41, \delta^{2} \mathrm{H}:-47,98 /-44,49,{ }^{3} \mathrm{H}: 2,58 / 2,35$ arasında; KS-7 için $\delta^{18} \mathrm{O}:-8,10 /-8,03$, $\delta^{2} \mathrm{H}:-43,10 /-42,13,{ }^{3} \mathrm{H}: 4,36 / 4,27$ arasında değiștiği saptanmıştır. KP-8 için $\delta^{18} \mathrm{O}:-8,33 /-8,37$, $\delta^{2} \mathrm{H}:-45,82 /-44,38 ;{ }^{3} \mathrm{H}: 3,75 / 2,48$ arasında değiştiği saptanmıştır (Çizelge 3 ve Çizelge 4). Kaynak sularındaki $\delta^{2} \mathrm{H}$ ve $\delta^{18} \mathrm{O}$ değerleri kullanılarak Döteryum fazlalığı $\mathrm{d}=\delta^{2} \mathrm{H}-8 . \delta^{18} \mathrm{O}$ formülü ile hesaplanmıştır [9]. Döteryum fazlalığının yüksek olduğu noktalar, denizel çökellerin yerine karasal çökellerin yaygın olduğu bölgelerde gözlenmiştir. Yedioluk-Kozan sahasındaki sularındaki df aralığının en düşük 19,78 ile HC-1'de, en yüksek değerinin de 23,77 ile ZT-2'de olduğu saptanmıştır (Çizelge 3 ve Çizelge 4). Duraylı izotop bileşimleri Yedioluk-Kozan sularının küresel meteorik (GMWL) ve Akdeniz su doğrularının (MWL) arasında yer aldığını göstermiştir. Bundan dolayı, bölgedeki su kaynaklarını oluşturan akiferlerin meteorik kökenli yağışlardan beslendiği ve yağışların buharlaşma etkisine girmeden akiferi beslediği sonucuna ulaşılmıştır (Şekil 7-A). Bu yorumlar neticesinde su kaynaklarını besleyen yer altı sularının, yağışların çatlak, kırık ve faylar boyunca süzülerek yeraltında birikmesi ile oluştuğu ve depolanan yer altı sularının tekrar fay ve etkili çatlaklar boyunca yükselerek yeryüzüne ulaştığı söylenebilir.

Çizelge 3. Su örneklerinin (Ocak 2017) izotop analiz sonuçları

\begin{tabular}{|c|c|c|c|c|}
\hline Numune adı & $\boldsymbol{\delta}^{\mathbf{1 8}} \mathbf{O}(\mathbf{\% o})$ & $\boldsymbol{\delta}^{\mathbf{2}} \mathbf{H}(\mathbf{\%}) \mathbf{0}$ & d-fazlalık (\%o) & Trityum (TU) \\
\hline HC-1 & $-8,1$ & $-4,30$ & 19,78 & 4,30 \\
\hline ZT-2 & $-8,55$ & $-7,10$ & 23,3 & 3,55 \\
\hline YO-3 & $-8,47$ & $-7,30$ & 20,64 & 3,60 \\
\hline YP-4 & $-8,68$ & $-7,79$ & 21,65 & 4,35 \\
\hline AC-5 & $-8,37$ & $-4,38$ & 22,58 & 2,48 \\
\hline KC-6 & $-8,41$ & $-4,49$ & 22,79 & 2,35 \\
\hline KS-7 & $-8,03$ & $-2,13$ & 22,11 & 4,27 \\
\hline KP-8 & $-8,21$ & $-4,73$ & 20,95 & 3,35 \\
\hline
\end{tabular}


Çizelge 4. Su örneklerinin Haziran ayı izotop analiz sonuçları

\begin{tabular}{|c|c|c|c|c|}
\hline Numune adı & $\boldsymbol{\delta}^{\mathbf{1 8}} \mathbf{O}(\mathbf{\%} \mathbf{0})$ & $\left.\boldsymbol{\delta}^{\mathbf{2}} \mathbf{H} \mathbf{( \% o}\right)$ & d-fazlalı (\%o) & Trityum (TU) \\
\hline HC-1 & $-8,21$ & $-4,68$ & 21,00 & 4,42 \\
\hline ZT-2 & $-8,74$ & $-6,15$ & 23,77 & 3,84 \\
\hline YO-3 & $-8,59$ & $-7,70$ & 21,02 & 3,64 \\
\hline YP-4 & $-8,85$ & $-8,02$ & 22,78 & 3,04 \\
\hline AC-5 & $-8,88$ & $-7,89$ & 23,15 & 4,55 \\
\hline KC-6 & $-8,44$ & $-5,98$ & 21,54 & 2,58 \\
\hline KS-7 & $-8,10$ & $-3,19$ & 21,61 & 4,36 \\
\hline KP-8 & $-8,33$ & $-5,82$ & 20,82 & 3,75 \\
\hline
\end{tabular}

${ }^{18} \mathrm{O}$ - Trityum grafiğine göre kaynak suları alçak kotlardan beslenmiş kısa dolaşımlı ve benzer yaşlı sulardır (Şekil 7-B). Yedioluk-Kozan su kaynaklarındaki ortalama Trityum $\left({ }^{3} \mathrm{H}\right)$ değerlerinin 2,35 ile 4,55 arasında değiştiği gözlenmiştir. Metorik kökenli suların yeraltında dolaşım süresi uzadıkça radyoaktif bozunmaya uğramaları ve böylece düşük trityum değerleri $\left({ }^{3} \mathrm{H}\right)$ sundukları dikkate alındığında, yüksek trityum ile birlikte düşük elektriksel iletkenlik değerleri gösteren Yedi Oluklar-Kozan kaynak sularının akiferle temas süresinin oldukça kısa olduğu söylenebilir. Cl-Trityum grafiğine göre, yüksek Trityum ve düşük $\mathrm{Cl}$ içerikleri bakımından su kaynaklarının temsil ettiği akiferin göreceli olarak kısa süreli geçiş zamanına sahip genç yeraltı suları ile beslendiği söylenebilir (Şekil 7-C). Ancak, Döteryum-Trityum ilişkisine göre KC-6 kaynağının dolaşım süresinin diğer su kaynaklarına göre biraz daha uzun olduğu belirlenmiştir (Şekil 7-D). Yüksek trityum konsantrasyonu ve düşük elektriksel iletkenlik değerleri, bölgedeki yeraltı sularında su-kayaç etkileşiminin kısa süreli olduğunu, yeraltı suyu bileşimi ile jeolojik birimler arasında belirgin bir etkileşim olmadığını ve yeraltı suyu alıkonma yaşının 50 yıldan az olduğunu göstermektedir [10], (Şekil 7-E).

\subsection{Su Kaynaklarının İnsan Sağlığına Etkisi}

İçme ve kullanma suyundaki kirleticiler özellikle çocuklara önemli zararlar verebilir. $\mathrm{Bu}$ kirleticilerden birisi nitrattır. Azot bileşiklerinden Nitrat $\left(\mathrm{NO}_{3}{ }^{-}\right)$, çevrede doğal olarak bulunan önemli bir besin elementidir. Nitratın içme suyu kaynaklarına ulaşım yolu çoğunlukla tarımsal faaliyetlerden (gübreler), katı atı sızıntı sularından, evsel ve endüstriyel atı su deşarjlarından kaynaklanmaktadır. Yani, yeraltı sularında ve içme suyu kaynaklarında görülennitrat kirliliğinin kökeni çoğunlukla doğal unsurlardan daha çok insan kaynaklı unsurlardır. USEPA kriterlerine göre sulardaki maksimum düzeyi 10 $\mathrm{mg} / \mathrm{L} \mathrm{NO}_{3}-\mathrm{N}$ veya $45 \mathrm{mg} / \mathrm{L} \mathrm{NO}_{3}$,tür. TS266 İnsani Tüketim Amaçlı Sular Standartları'na göre kaynak suları için olması gereken maksimum nitrat sınırı $25 \mathrm{mg} / \mathrm{L}$ 'dir. $\mathrm{Bu}$ düzeyin üzerindeki değerler kronik zehirlenme ile çeşitli sağlık problemlerine ortaya çıkmasına neden olmaktadır. İnsan vücuduna giren nitrat çeşitli reaksiyonlar sonucunda insan ve hayvanlarda kanserojen etki gösteren bileşiklere dönüşür. Ayrıca, nitratın vücuda alındıktan sonra daha zararlı ve kararsız bir ara ürün olan nitrit formuna dönüştüğü ve beraberinde nitrosamit/nitrosamin formlarına dönüşerek kanserojenik etkiye sebep olduğu bilinmektedir [11]. Çalışma alanında yapılan su kalitesi analizlerinde su numunelerinin özellikle nitrat derişimlerinin yüksek olduğu ve sınır değerleri aştığı belirlenmiştir.

Sülfat $\left(\mathrm{SO}_{4}^{-2}\right)$ ise doğada genellikle sülfat mineralleri halinde bulunur. En yaygın bileşikleri alçı $\left(\mathrm{CaSO}_{4} .2 \mathrm{H}_{2} \mathrm{O}\right)$, anhidrit $\left(\mathrm{CaSO}_{4}\right)$, barit $\left(\mathrm{BaSO}_{4}\right)$ ve sölestin $\left(\mathrm{SrSO}_{4}\right)$ 'dir [12]. Sülfatın tat eşiği, sülfat tuzu olarak $250 \mathrm{mg} / \mathrm{L}$ olarak verilebilir [13]. Sodyum sülfat ve magnezyum sülfatın yüksek derişimleri insanlarda müshil etkisi yaratacağından $500 \mathrm{mg} / \mathrm{L}$ ve üzerine çıkan sülfat seviyelerinin içme suyu kaynaklarında tespit edilmesi halinde, sağlık yetkililerinin bilgilendirilmesi önerilmektedir [14]. 

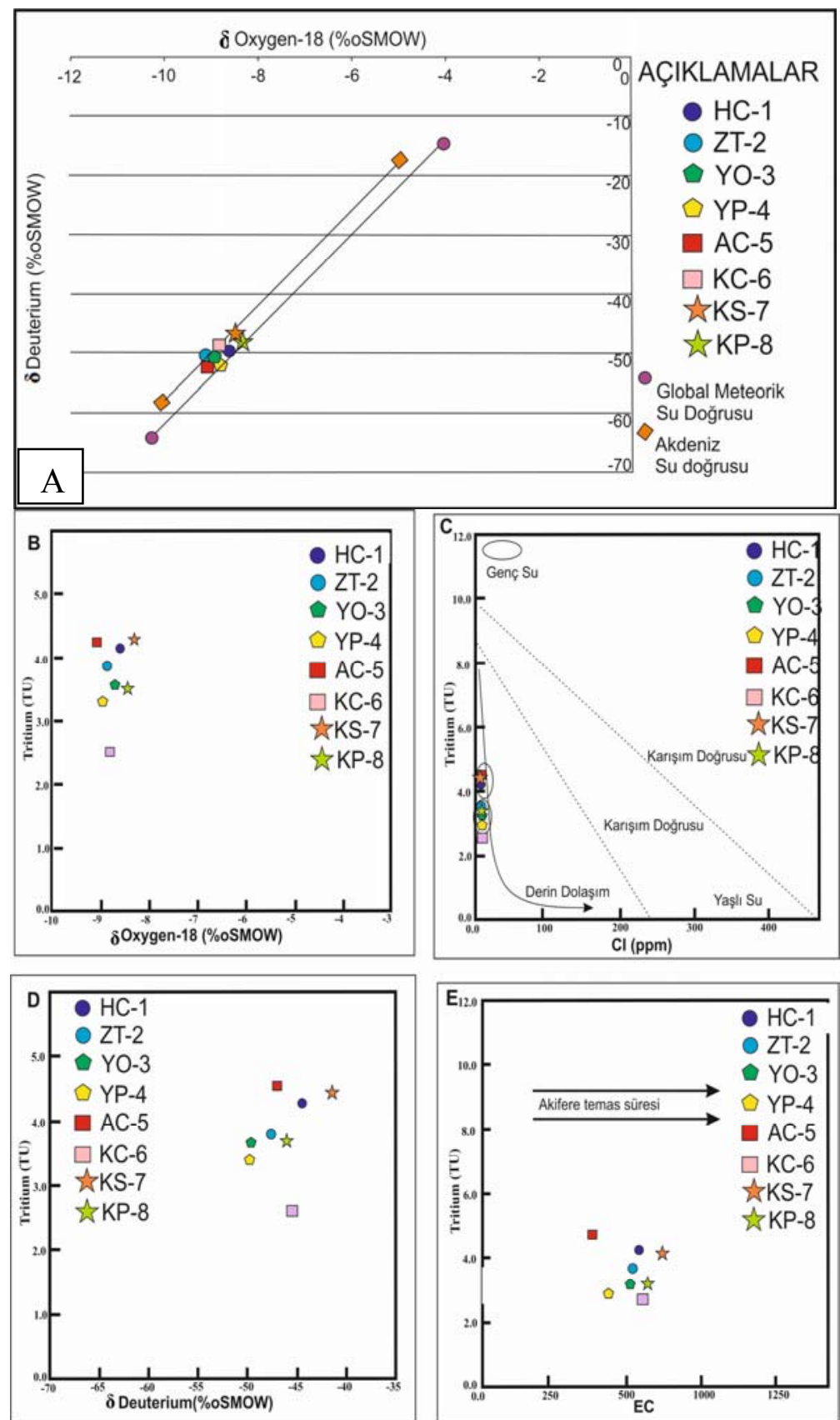

Şekil 7. Yedioluk-Kozan sahasındaki su kaynaklarının Globalmeteorik (GMWL) ve Akdeniz su doğrularının (MWL) $\delta^{18} \mathrm{O}-\delta^{2} \mathrm{H}$ ilişskisi

Standart değerlerle karşılaştırıldığında YediolukKozan içme suları Tıbbi jeoloji açısından değerlendirildiğinde, bölgedeki HC-1, ZT-2,
YO-3, YP-4, AC-5 ve KC-6 olarak adlandirılan su kaynakları, özellikle nitrat yönünden normal içme suyu standartları değerinin üzerindedir. 


\section{SONUÇLAR}

Yedioluk-Kozan bölgesindeki Hamam Çeşmesi (HC-1), Ziyaret Tepe (ZT-2), Köy Çeşmesi (YO-3), Yatır Pınarı (YP-4), Aşağı Köy Çeşmesi (AC-5), Kozan Köy Çeşmesi (KC-6), Kozan Köyü Sondaj Yeri (KS-7) ve Kozan Köyü Pınarından (KP-8) bir yıl boyunca aylık olarak toplanan su numunelerin de fiziksel ve kimyasal parametrelerin analizleri gerçekleştirilmiştir. Analiz sonuçları neticesinde; KS-7 ve KP-8 kaynakları haricinde diğer tüm kaynakların TS 266 standardlarına uygun olmadığı, özellikle nitrat derişimlerinin yüksek olduğu belirlenmiştir. $\mathrm{Bu}$ sebeple, bu bölgedeki su kaynaklarında nitrat giderilmesine yönelik çalışmalar yapılması önem arz etmektedir. Bölgedeki su kaynaklarının içinde bulunduğu kireçtaşı, silisli şeyi ve radyolaritlerden oluşan Koçali formasyonunun uygun litoloji sunmasından dolayı oluştuğu gözlemlenmiştir. Schoeller diyagramında değerlendirilen analiz sonuçlarına göre, suların aynı kökenli ve benzer akifer litolojilerine sahip oldukları belirlenmiştir ve Piper diyagramına göre kaynaklar 6 . bölgeye düşmektedir. Karbonat olmayan sertliği \%50’den fazla sulara aittir ve karbonat olmayan sertliği yani kalıcı sertliği geçici sertliğine göre daha yüksek bu tip suların genellikle $\mathrm{CaSO}_{4}, \mathrm{MgSO}_{4}, \mathrm{CaCl}_{2}$,ve $\mathrm{MgCl}_{2}$ olan sulardır. Schoeller Diyagramında kaynak sularının ppm değerlerini birleştiren doğruların birbirine paralel geçtiği görülmektedir. Buda bu suların aynı akiferden beslendiğini göstermektedir. İzotop sonuçlarına göre Döteryum ve Oksijen-18 grafiğine baktığımızda, yerel meteorik su doğrusuna ve Akdeniz su eğrisine yakın yerlerine düşmektedir. $\mathrm{Bu}$ da bize kaynakların meteorik bir su olduğunu ve yağışlarla beslendiğini söylemektedir. Döteryum-Trityum ilişkisi ise bize KC-6 Kozan köy çeşmesi su kaynağının derin sirkülasyon, diğerlerinin ise sığ bir sirkülasyon sunduğunu göstermektedir. Oksijen-18 ve Trityum değerlendirilmesinde bütün su kaynaklarının 50 yılın altında olan genç sular sınıfına girdiği belirlenmiştir. Bölgenin içinde bulunduğu Koçali formasyonunun genel litolojik özellikleri arasında büyük bir uyum olduğu gözlenmiştir. Buna göre Yedi Oluklar-Kozan mevkii su kaynaklarının bulunduğu alanda, Üst Jura-Alt Kretase yaşlı Koçali Kompleksi formasyonu başlica volkano-sedimanter ve ofiyolitik kaya topluluğundan oluşur. Çalışma alanında bulunan söz konusu su kaynakları bu ofiyolitlerin sağladığı kırık ve çatlaklı litoloji içinden gelmektedir. Derin olmayan akiferler yardımıyla Koçali formasyonun üst kısmına kadar süzülen sular döngüye katılmaktadır. Bu akifer sistemindeki kısa süre kalan sular daha sonra değişik su kaynakları olarak yüzeye çıkmaktadır. Tibbi jeoloji açısından değerlendirilen su kaynaklarının 6'sı nitrat bileşimince zengin olup sağlık açısından olumsuz sonuçlar doğurmaktadır. Bölgede yaşayan köy halkının büyük bir çoğunluğunda kanser vakalarının yaşandığ bunun yüksek nitrat içeriği ile ilgili olabileceği düşünülmektedir. Ancak, konu ile ilgili ayrıntılı çalışmalar yapılması gerekmektedir.

\section{TEŞEKKÜR}

Bu makale; Kahramanmaraş Sütçü İmam Üniversitesi Bilimsel Araştırmalar Birimi tarafından desteklenmiştir

\section{KAYNAKLAR}

1. Akın, G., Akın, M., 2007. Galip Suyun Önemi, Türkiye'de Su Potansiyeli, Su Havzaları ve Su Kirliliği, Ankara Üniversitesi Dil ve TarihCoğrafya Fakültesi Dergisi. 47(2):105-118.

2. Sungurlu, O., 1973. VI. Bölge Gölbaşı-Genger Arasındaki Sahanın Jeolojisi: TPAO Arama Grubu, Rapor No: 802, Ankara.

3. Sungurlu, O., 1974a. VI. Bölge Kuzey Sahalarının Jeolojisi: TPAO Arama Grubu, Rapor No: 871, 32, Ankara.

4. Sungurlu, O., 1974b. VI. Bölge Kuzey Sahalarının Jeolojisi: Türkiye İkinci Petrol Kongresi Tebliğleri, 85-107, Ankara.

5. Duran, O., Şemşir, D., Sezgin, İ., Perinçek D., 1988. Güneydoğu Anadolu'da Midyat ve Silvan Gruplarının Stratigrafisi, Sedimantolojisi ve Petrol Potansiyeli, TPJD Bü1t. 2, 99-126.

6. World Health Organization. 1998. WHO Disablements Assessment Schedule II (WHO DAS II). Geneva, Switzerland: World Health Organization. 
7. Piper, A.M., 1944. A Graphic Procedure in Geochemical Interpretation of Water Analyses. Transactions, American Geophysical Union, 25, 914-923.

8. Craig, H., 1961. Isotopic Variations in Meteoric Waters, Science, 133, 1833-1834.

9. Dansgaard, W., 1964. Stable Isotopes in Precipitation, Tellus, XVI (4), 436-468

10. Carreira, P.M., Marques, J.M., Nunes, D., Santos, F.A.M., Gonc Alves, R., Pina, A., Gomes, A.M., 2013. Isotopic and Geochemical Tracers in the Evaluation of Groundwater Residence Time and Salinization Problems at Santiago Island, Cape Verde. Earth and Planetary Science, 7, 113-117.

11.AWWA. 2011. Water Quality and Treatment-A Handbook on Drinking Water. ( $6^{\text {th }}$ edition) ABD: Mc Graw Hill.

12. Jack J. Middelburg, Joop Nieuwenhuize (2000) Nitrogen uptake by heterotrophic bacteria and phytoplankton in the nitrate-rich Thames estuary MARINE ECOLOGY PROGRESS SERIES. Vol. 203: 13-21, 2000.

13. World Health Organization. 2004 b. The Guidelines for Drinking-Water Quality

14. World Health Organization. 2011. The Guidelines for Drinking-Water Quality $\left(4^{\text {th }}\right.$ ed.). World Health Organization, Geneva. 
